\title{
Bullying in the Australian ICT workplace: the views of Australian ICT professionals
}

\author{
Yeslam Al-Saggaf \\ School of Computing and Mathematics, \\ Charles Sturt University \\ yalsaggaf@csu.edu.au
}

\section{Arnela Ceric}

School of Management and Marketing, Charles Sturt University

\section{Abstract}

The aim of this study is to examine bullying in the workplace from the perspective of Australian Information Communication Technology (ICT) professionals. The data collection for this project included conducting a quantitative survey with 2,315 participants and 43 qualitative interviews with members of Australian Computer Society (ACS). We found that 630 ICT professionals, or $27.23 \%$ of all survey respondents, identified workplace bullying as an ethical problem. The majority of survey respondents who selected bullying as an ethical issue were permanent full time employees $(\mathrm{N}=413,65.6 \%)$. A significant relationship was found between respondents identifying bullying as an ethical issue in the survey and their job classification (Deviance $=25.55, \mathrm{Df}=11, \mathrm{p}=0.0076$ ), suggesting that job classification, among other things, does predict respondents' selection of bullying. Furthermore, our survey and interview findings indicate that the more mature respondents, as well as those in the managerial roles, have a greater concern about bullying.

Keywords: ICT professionals; Professional ethics; bullying; harassment.

\section{Introduction}

Bullying is a major problem in the workplace (Standen, Paull \& Omari, 2014). It reduces employee's productivity, motivation and wellbeing (Cowie, Jennifer, Neto, Angula, Pereira, Del Barrio, \& Ananiadou, 2000) and affects the overall work environment and organisational climate (Kelloway, Bryant, Buttigieg, \& Hanley, 2009; Harvey, Heames, Richey, \& Leonard, 2006). Overall, the outcomes are negative for both, employers and employees. However, to our knowledge, no research has been done into workplace bullying in the Australian ICT industry. The ICT workplace is distinct due to gender imbalance (Oleksy, Just, \& Zapedowska-Kling, 2012) and requirements for high technical knowledge. Thus, the purpose of this paper is to present findings on bullying from the perspective of Australian ICT professionals, based on a research project that examined professional ethics more broadly in the ICT workplace in Australia.

As part of the project on ethics in ICT workplace, two stages of data collection were used. In the first stage, a quantitative survey was conducted with 2,313 members of the Australian Computer Society (ACS), administered using SurveyMonkey. Survey data identified workplace bullying to be one of the top ten ethical problems faced by ICT professionals (see Table 2). Based on the survey data, we identified demographic variables of survey respondents who identified bullying as one of the ethical issues they faced. Understanding these demographic variables seems relevant for identifying a general profile of ICT professionals who are concerned about bullying. The second stage of the project involved conducting semi-structured interviews with 43 participants. Interviewees were selected from the group of survey respondents in the earlier stage of the data collection process. Qualitative interviews with ICT professionals provided additional insights into the forms that bullying takes in the ICT workplace. 
The structure of the paper is as follows. Literature on workplace bullying and the demographic characteristics of participants on bullying are explored in the first section. Quantitative research methodology and the findings from the survey are presented in the second section, followed by discussion on semi-structured interviews and the findings from the interviews. In the last section of the paper, the findings are discussed and concluding remarks are provided.

\section{Workplace bullying}

Workplace bullying and workplace harassment are used interchangeably in the literature (Skinner, Peetz, Strachan, Whitehouse, Bailey \& Broadbent, 2015). Workplace bullying can "involve one or more perpetrators and targets at various levels of the organization, occur at various degrees of severity and frequency, be intentional or unintentional, and manifest in a wide variety of unacceptable behaviours in response to various precipitants" (Crawshaw, 2009, p.265). The definition provided here is a generic one so that it can encompass a range of bullying situations and contexts. For example, Harvey et al. (2006) identified five groups of behaviours related to workplace bullying. These behaviours are related to isolation by preventing access to opportunities or withholding important information, threats to personal standing by insulting or teasing the victim overwork through an increase of workload to targeted individuals, as well as reminding the victim of their failures, and humiliating them in public which can damage their professional status.

Definitions of workplace bullying have several components, namely, a) the targets of bullying experience negative behaviour persistently, b) the targets of bullying experience psychological or physical harm, c) they label the experience as bullying, d) the targets of bullying cannot defend themselves, and e) the targets of bullying perceive themselves as having less power than the bully (Keashly \& Neuman, 2004).

Definitions provided in the literature may be different from personal definitions of workplace bullying. Saunders, Huynh, and Goodman-Delahunty (2007) found that lay people include two essential aspects of workplace bullying commonly used in the literature. These are occurrences of a negative behaviour (reported by $98.3 \%$ of their participants) and some form of harm that such behaviour causes to the target (86.3\%). In addition, participants identified two additional components of workplace bullying that are not included in the literature. According to their definition, bullying involves unprofessional behaviour that violates the way employees are expected to be treated in a workplace (25.5\%), and it needs to be intentional in order to be defined as bullying (21.4\%). Moreover, participants rarely included non-essential elements of bullying in their definitions. According to them, bullying does not need to be persistent or involve power imbalance, and targets do not need to self-label their experiences as bullying.

Workplace bullying represents a major source of stress at work that can cause severe social, psychological and psychosomatic problems for the victims (Standen, Paull \& Omari, 2014). Victims of workplace bullying may suffer from post-traumatic stress syndrome (Leymann \& Gustafsson, 1996; Rodríguez-Muñoz, Moreno-Jiménez, Sanz Vergel, \& Garrosa Hernández, 2010) as well as insomnia, melancholy, lack of concentration, apathy, socio-phobia (Bjorkqvis, Osterman, \& Hjelt-Back, 1994), depression (Zapf, 1999), chronic and cardiovascular diseases (Kivimäki, Virtanen, Vartia, Elovainio, Vahtera, \& Keltikangas-Järvinen, 2003). Apart from targets, workplace-bullying has a significant effect on bystanders as well. For example, Vartia (2001) found that both, victims and observers of bullying experience higher rates of general and mental stress in comparison to employees who did not experience or observe bullying.

Bullying affects organisational performance through higher rates of absenteeism, staff turnover, reduced efficiency, decline in work quality, increased error margins and an unsafe workplace (Skinner et al., 2015; Kelloway et al., 2009; Sheehan, McCarthy, Barker, \& Henderson., 2001). In addition, Zapf (1999) reported that workplace bullying creates negative working conditions due to lack of communication, conscious miscommunication and conflicts. Moreover, Harvey et al. (2006) reported four outcomes of workplace bullying that negatively affect organisational performance. Victims' job-related abilities can decrease, their innovative behaviour can be eliminated, organisational level of flexibility and adaptability can be 
decreased, and long-term success of the organisation can be shattered. Participants in Cowie et al.'s (2000) study report that bullying reduced their wellbeing, motivation and efficiency.

There are multiple causes of workplace bullying (Salin, 2003b; Zapf, 1999). For example, Leymann (1993) identified deficiencies in work design and leadership behaviour, as well as a socially exposed position of the victim and a low moral standard in the work environment as causes of harassment. Hauge, Skogstad, and Einarsen (2009) found that being a male and being a target of bullying, as well as role conflict and interpersonal conflict strongly predict being a bully. In addition, Notelaers, De Witte, and Einarsen (2010) found that role conflict and role ambiguity cause bullying at work. Vartia (1996) found that psychological work environment and organisational climate explain $24 \%$ of the variance in bullying. Furthermore, victims surveyed in Vartia's (1996) study reported envy, a weak superior and competition for tasks, advancement or superior approval as reasons for why they were bullied. Zapf (1999) found that victims saw organisational climate, high stress and organisational problems as causes of workplace bullying. Some victims reported personal reasons for bullying, such as low performance, deficits in social skills, 'being difficult', aggressive or moaning. In addition, Claybourn (2011) examined the relationship between moral disengagement, work characteristics and workplace harassment. He found that employees who are morally disengaged are more likely to report that they have been subjected to workplace harassment, and ultimately, they themselves participate in harmful behaviours towards others. Salin (2003b) concluded that bullying is a result of interaction between three groups of factors associated with workplace bullying. These are enabling structures (e.g., power imbalances, dissatisfaction), incentives (e.g., internal competition, expected benefits) and triggering circumstances (e.g., organisational changes).

Definitions of bullying discussed here (Saunders et al., 2007) and the specific forms that bullying takes identified by Harvey et al. (2006) will be further compared with the findings from the qualitative component of this study. This will shed more light into the forms that bullying behaviour takes in the Australian ICT workplace.

\section{Demographic characteristics of participants in studies on ethical issues and bullying}

\subsection{Age}

Age is an important demographic characteristic that influences ICT professionals' awareness of ethical issues. Wilford and Wakunuma (2014) found that more mature ICT professionals have a significantly higher level of ethical awareness in comparison to younger ICT professionals. The latter group was more concerned with process and compliance with the requirements of their organisation, and was relatively unaware of ethical issues.

Age also influences the emphasis that ICT professionals place on ethical regulations. Lucas and Mason (2008) found that Generation Y ICT professionals, that is, those born in 1980 s and 1990 , are different from other generations in regards to the importance they place on ethical regulations. Generation Y put less emphasis on ethical regulations and think that they ought to be less important. This finding is relevant for decision-making in the ICT field as the importance placed on ethical regulations can have an impact on the judgement of decisionmakers. However, the ethical awareness in Wilford and Wakunuma's (2014) and the emphasis placed on ethical regulations in Lucas and Mason's (2008) studies relate to issues in ICT, such as trust, social exclusion, privacy, and misuse of technology, not to workplace bullying.

Notelaers, Vermunt, Baillien, Einarsen, and De Witte (2011) found that employees above 54 years and those less than 25 years of age are least likely to be bullied at work, while employees in the age group between 35 and 44 have the highest risk of workplace bullying, followed by those aged between 25 and 34. Similarly, Einarsen and Raknes (1997) as well as Bowling and Beehr (2006) found that older men experience less victimisation than younger men. In contrast, Einarsen and Skogstad (1996) found that older workers had a higher risk of victimisation than the younger employees. Vartia (1996) found a small correlation between age 
and bullying. On the other hand, Ortega, Høgh, Pejtersen, and Olsen (2009) did not find age to be important in explaining the prevalence of bullying.

\subsection{Gender}

One of the characteristics of the ICT industry is unequal participation of men and women in ICT employment (Oleksy, et al., 2012). There is some research that found that women are more ethical than men when it comes to ICT ethical issues (Mason \& Mudrack, 1996; Valentine \& Page, 2006) and that this has a favourable impact on the organisation's bottom line (Quigley \& Mohamad, 2008). In contrast, Young and Case (2009) examined a general population and found that there were no significant gender differences in the perception of unethical ICT behaviour. On the other hand, Lucas and Mason (2008) found that male ICT professionals thought that ethical regulations should be less important, in comparison to female ICT professionals. Mudrack and Mason (2013) concluded that gender does not impact on ethical judgement. However, in cases when the difference occurs, women judged ethically questionable activities as being less appropriate than men.

Salin (2003a) explains the complexity between gender and workplace bullying, although this has received little attention in research. Perpetrators of bullying are most likely to be males who have been a target of bullying themselves (Hauge et al., 2009). Female workers report higher victimisation rates when they occupy middle and senior management roles (Hoel, Cooper, \& Faragher, 2001), and when they are in non-traditional jobs (Gutek \& Morasch, 1982). Male workers and supervisors report that they observe general and workplace bullying more often than women in the same roles (Hoel et al., 2001), but they do not identify themselves with being bullied when asked directly (Jóhannsdóttir \& Ólafsson, 2004). Women report being bullied by their superiors, colleagues and subordinates of both genders, while men tend to be bullied by male supervisors and to a smaller extent by their colleagues (Salin, 2003a). Men tend to confront when bullied, women tend to seek help or avoid the situation (Jóhannsdóttir \& Ólafsson, 2004), often by leaving the organisation (Salin, 2003a). Griffiths and Moore (2010) found that bullying is one of the main reasons why women in the UK left the ICT sector.

\subsection{Occupation}

Occupations such as teachers and managers, as well as nurses and social services have a low chance of being bullied. This can be related to relatively lower workload and high level of autonomy. Salin (2001) found that managers indeed have a lower risk of being a victim of bullying, while this risk increases for experts, middle managers and officials/clerks. Workplace bullying among business professionals in managerial and expert positions is found to be higher when using a predefined list of negative acts of bullying (24.1\%), than when respondents classify themselves as being bullied (8.8\%) (Salin, 2001). Furthermore, managers and supervisors have been identified as perpetrators rather than victims of bullying (Cowie et al., 2000).

Ortega et al. (2009) found that occupational status and type of work processes were important indicators of workplace bullying. That is, unskilled workers were found to have the highest prevalence of bullying, while managers and supervisors had the lowest prevalence. In addition, respondents working with things reported the highest prevalence of bullying, while respondents working with customers, the lowest. Ortega et al. (2009) did not find age or gender as important as type of work in explaining the prevalence of bullying. Notelaers et al. (2011) also found that blue-collar workers have a higher risk of workplace bullying as compared to white-collar employees.

\subsection{Job classification and years of experience}

Prior research has shown that full-time employees have a higher chance of being bullied in comparison to temporary employees (Notelaers et al., 2011). Bowling and Beehr's (2006) meta-analysis found that employees with longer tenure were more likely to be victimised than were those with shorter tenure. Cowie et al. (2000) found that length of current job was the 
only demographic characteristic that significantly correlates experiencing bullying behaviours in their UK sample. These findings can be explained with the entrapment hypothesis which states that permanent employees are less likely to move jobs when working conditions deteriorate (Cuyper, Notelaers, \& Witte, 2009).

The demographic characteristics discussed here will be further compared with the demographic characteristics of the participants who selected bullying in the survey and the interviewees who raised the issue of bullying during interviews. This should shed light into the groups of participants/interviewees who are concerned about bullying in the Australian ICT workplace.

\section{Methods and findings}

\subsection{The quantitative survey}

\subsubsection{Survey procedure}

The first stage of the data collection process involved a survey administered using SurveyMonkey to allow the participants to complete the survey and return it over the internet. The survey was informed by the results of a 2006 survey conducted by Lucas and Weckert (2008) and also by the instrument they used. All active ACS members (approximately 18,600) were invited to participate in the web-based survey by direct email sent to them by the ACS once on 12 September 2013. The survey was closed on 6 November 2013 after the response rate reached $12.4 \%$. The online survey was prefaced by the ethics consent sheet (including assurances of anonymity) and a description of the study. The questions comprised both closed and open-ended questions. This study reports only on the closed questions.

\subsubsection{Sample}

A total of 2,315 participants completed the survey. The average number of years of work experience for all respondents was 19 years. However, 61.6\% of those who selected bullying as one of the most common problems had more than 20 years of experience. Table 1 shows a summary of the demographic information of all participants as well as the demographic information for the participants who selected bullying as one of the most common problems. As can be seen from Table 1, it appears that the overall profile of the survey respondents is not much different from the profile of the selectors of bullying as one of the most common problems. 


\begin{tabular}{|c|c|c|c|c|c|}
\hline \multicolumn{2}{|c|}{ Demographic information } & \multicolumn{2}{|c|}{$\begin{array}{c}\text { Survey } \\
\text { participants }\end{array}$} & \multicolumn{2}{|c|}{$\begin{array}{l}\text { Participants } \\
\text { who selected } \\
\text { bullying }\end{array}$} \\
\hline & & $\mathrm{N}$ & $\%$ & $\mathrm{~N}$ & \\
\hline \multirow{3}{*}{ Gender } & Female & 356 & 15.5 & 113 & 17.9 \\
\hline & Male & 1,940 & 83.9 & 513 & 81.4 \\
\hline & N/A & 17 & 0.7 & 4 & 0.6 \\
\hline \multirow[t]{5}{*}{ Age } & $<35$ & 692 & 30 & 155 & 24.6 \\
\hline & $36-45$ & 516 & 22.3 & 148 & 23.5 \\
\hline & $46-55$ & 576 & 25 & 174 & 27.7 \\
\hline & $>56$ & 524 & 22.7 & 153 & 24.3 \\
\hline & N/A & 5 & 0.2 & 0 & O \\
\hline \multirow[t]{10}{*}{ State } & $\mathrm{ACT}$ & 247 & 10 & 80 & 12.7 \\
\hline & NSW & 696 & 30.4 & 199 & 31.6 \\
\hline & NT & 27 & 1.2 & 8 & 1.3 \\
\hline & QLD & 279 & 12.2 & 81 & 12.9 \\
\hline & SA & 120 & 5.5 & 28 & 4.4 \\
\hline & TAS & 42 & 1.8 & 10 & 1.6 \\
\hline & VIC & 581 & $25 \cdot 4$ & 149 & 23.7 \\
\hline & WA & 218 & 9.5 & 57 & 9.0 \\
\hline & Overseas & 80 & 3.5 & 14 & 2.2 \\
\hline & $\mathrm{N} / \mathrm{A}$ & 23 & 1.0 & 4 & 0.6 \\
\hline \multirow[t]{8}{*}{ Occupation } & Administrator & 134 & 6.5 & 36 & 5.7 \\
\hline & Consultant & 502 & 24.3 & 146 & 23.2 \\
\hline & Developer & 307 & 14.8 & 77 & 12.2 \\
\hline & Education & 150 & $7 \cdot 3$ & 43 & 6.8 \\
\hline & Manager & 698 & 33.8 & 196 & 31.1 \\
\hline & Technical Support & 277 & 13.3 & 76 & 12.1 \\
\hline & Other & 215 & 10.39 & 54 & 8.6 \\
\hline & $\mathrm{N} / \mathrm{A}$ & 247 & 11.9 & 2 & 0.3 \\
\hline \multirow{3}{*}{$\begin{array}{l}\text { Geographical } \\
\text { Location }\end{array}$} & Capital City & 2,069 & 89.5 & 581 & 92.2 \\
\hline & Regional Area & 215 & 9.43 & 46 & $7 \cdot 3$ \\
\hline & N/A & 29 & 1.3 & 3 & 0.5 \\
\hline \multirow[t]{11}{*}{$\begin{array}{l}\text { Job } \\
\text { Classification }\end{array}$} & $\begin{array}{l}\text { Business owner with } \\
\text { employed staff }\end{array}$ & 57 & 2.7 & 8 & 1.3 \\
\hline & Fixed term contract & 251 & 11.8 & 83 & 13.2 \\
\hline & Indefinite contract & 34 & 1.6 & 8 & 1.3 \\
\hline & Permanent Full-Time & 1,388 & 65.4 & 413 & 65.6 \\
\hline & Permanent Part-time & 90 & 4.2 & 17 & 2.7 \\
\hline & Self-Employed & 112 & $5 \cdot 3$ & 26 & 4.1 \\
\hline & Temporary Full-time & 61 & 2.9 & 11 & 1.7 \\
\hline & Temporary Part-time & 63 & 3.0 & 16 & 2.5 \\
\hline & Volunteer & 67 & 3.2 & 13 & 2.1 \\
\hline & Other & 121 & 5.69 & 33 & 5.2 \\
\hline & N/A & & & 2 & 0.3 \\
\hline
\end{tabular}

Table 1: Demographic characteristics of the survey participants and those who selected bullying as an ethical issue in the survey

\subsubsection{Statistical analysis}

Multiple Response Frequency (MRF) analysis and cross tabulations

Participants were asked in the survey to choose among different ethical problems they experienced in the workplace. Since respondents were allowed to select more than one answer, a Multiple Response Frequency (MRF) analysis (Al-Saggaf, Burmeister \& Weckert, 2016) was 
judged to be the most appropriate technique for analysing the survey data. In addition, cross tabulations were performed to see if there are differences in responses based on the demographic information. The findings from the MRF analysis are summarised below.

The MRF analysis revealed that bullying was ranked ninth in a list of the most common ethical problems experienced by ICT professionals $(\mathrm{N}=630,27.2 \%)$. Table 2 lists the top 10 ethical problems along with the number of responses and their percentages. The focus of this paper is on workplace bullying, and thus discussion on other ethical issues presented in Table 2 is outside the scope of this paper.

\begin{tabular}{lcc}
\hline \multicolumn{1}{c}{ Ethical problems } & \multicolumn{2}{c}{$\begin{array}{c}\text { Number of survey } \\
\text { respondents }\end{array}$} \\
& $\mathrm{N}$ & $(\%)$ \\
\hline Compromising quality to meet deadlines & 1104 & 47.7 \\
Blaming others for own mistakes & 957 & 41.4 \\
Compromising functionality to meet deadlines & 846 & 36.6 \\
Overworking staff & 762 & 32.9 \\
Incompetence & 750 & 32.4 \\
Conflict of interest & 682 & 29.5 \\
Unprofessional behaviour & 633 & 27.4 \\
Compromising user requirements to meet deadlines & 632 & 27.3 \\
Bullying & 630 & 27.2 \\
Compromising security to meet deadlines & 611 & 26.4 \\
\hline
\end{tabular}

Table 2: The top 10 ethical problems faced by Australian ICT professionals

\section{Generalised linear models}

To investigate which demographic variables predict respondents' selection of bullying in the survey, Generalised Linear Models (GLMs) were used. The responses to the bullying question are binomial (recorded as a Yes/No), whereas all the demographic variables are categorical. For this reason GLMs were fitted to investigate the relationships between the predictor variables and the binomial response variable. The GLMs were carried out on the data using R (version 3.0.2) and all requirements of this analysis were verified.

The analysis of deviance revealed that there is a significant relationship between respondents' selection of bullying as an ethical issue in the survey and Age, Gender, Geographic Location, Job Classification, and Years of Experience (see Table 3 for the results of the analysis of deviance). All other demographic variables showed no evidence of a relationship with respondents' selection of bullying in the survey. The fact that the statistical analysis (the analysis of deviance) showed that Age, Gender, Geographic Location, Job Classification and Years of Experience all predict the survey respondents' selection of bullying raises a question: what are the demographic characteristics of the interviewees who raised the issue of bullying during the interviews. This question will be addressed in the subsequent section titled 'Comparison between the survey participants and interviewees who raised the issue of bullying in the survey/interview'.

\begin{tabular}{lccc}
\hline $\begin{array}{c}\text { Demographic } \\
\text { variable }\end{array}$ & Deviance & $\begin{array}{c}\text { Degrees of } \\
\text { freedom (DF) }\end{array}$ & $\boldsymbol{P}$ \\
\hline Age & 18.02 & 8 & 0.0211 \\
Gender & 4.15 & 1 & 0.0416 \\
Geographic Location & 4.58 & 1 & 0.0324 \\
Job Classification & 25.55 & 11 & 0.0076 \\
Years of Experience & 13.92 & 1 & 0.0002 \\
\hline
\end{tabular}

Table 3: The analysis of deviance 
GLM was also used to examine whether there is a relationship between the perceived frequency of occurrence of unethical behaviour and the respondents' selection of bullying. This technique is fitted to investigate this relationship since the predictor is also a categorical variable. The analysis of deviance revealed that there is a significant relationship between the perceived frequency of occurrence of unethical behaviour and respondents' selection of bullying (Deviance $=143.29, \mathrm{Df}=4, \mathrm{p}=0.0000$ ) suggesting that this variable is also a predictor for respondents' selection of bullying in the survey.

Notelaers et al. (2011) found that employees above 54 years and those less than 25 years of age are least likely to be bullied at work, while employees in the age group between 25 and 44 have the highest risk of workplace bullying. However, a more recent literature from the academic sector, specifically Skinner et al. (2015), has indicated that older employees are more likely to be bullied than their counterparts. In the current study, the analysis of deviance showed that age predicted the selection of bullying in the survey. We found that $51.2 \%$ participants between 36 and 55 years of age selected bullying as a common ethical problem. In comparison, only $24.6 \%$ or younger participants between 18 and 35 years of age, and $24.3 \%$ of participants older than 56 years also identified bullying as an ethical issue in the survey. This suggests that middle-aged participants are more concerned about bullying than participants in other age categories. This finding is consistent with Notelaers et al.'s (2011) finding that middle-aged employees are more likely to be bullied at work, but is not in line with Skinner et al.'s (2015) finding that older employees are more likely to be bullied at work.

Gender was also found to be a predictor for the selection of bullying in this study. Almost $18 \%$ of interviewees who selected bullying were females. In comparison to the $15.5 \%$ females who participated in the survey, this finding suggests a higher proportion of females working in ICT could be victims of bullying; but this is a question for future research. Similarly, Job Classification was also found to be a predictor for the selection of bullying. However, the finding that a higher proportion of permanent full time employees (65.6\%) and fixed term contracts (13.2\%) selected this problem in our survey is aligned with the literature. The literature suggests that full time employees have a higher chance of being bullied in comparison to temporary employees (Notelaers et al., 2011).

\subsection{The qualitative interviews}

\subsubsection{Conducting the interviews and analysing the data}

The survey was followed by a set of semi-structured interviews with 43 participants selected from the pool of survey participants in the previous stage of the data collection process. The interviews were conducted during the month of February 2014 and took place in the six capital cities of the Australian states. All interviews were audio recorded and transcribed verbatim.

The invitation for participation was sent to all survey participants who indicated their willingness to participate in the interviews. However, during the interviewing stage only some confirmed their willingness to participate in the interviews. Interviewees were selected based on their demographic characteristics to ensure that we captured a diversity of views representative of those who work in ICT. The results of the GLMs did not influence the choice of the participants in the interviews as the purpose of these follow-up interviews was to explore participants' perceptions of the nature of the ethical problems experienced in the ICT workplace.

The final sample of interviewees included professionals from a range of ICT organisations, both large and small, representing different geographic locations, ages, genders, types of jobs, and employment experience. Table 4 lists demographic characteristics of the interviewees who participated in this research project. It should be noted that only 10 (out of 43) interviewees raised the issue of bullying during interviews. Their views on bullying are further reported in the next section. 


\begin{tabular}{|c|c|c|c|c|c|}
\hline \multicolumn{2}{|c|}{ Interviewees' characteristics } & \multicolumn{2}{|c|}{ Interviewees } & \multicolumn{2}{|c|}{$\begin{array}{l}\text { Interviewees who } \\
\text { raised bullying }\end{array}$} \\
\hline & & $\mathrm{N}$ & (\%) & $\mathrm{N}$ & (\%) \\
\hline \multirow[t]{2}{*}{ Gender } & Female & 7 & 16.28 & 1 & 2.3 \\
\hline & Male & 36 & 83.72 & 9 & 21 \\
\hline \multirow[t]{4}{*}{ Age } & $<35$ & 5 & 11.63 & 1 & 2.3 \\
\hline & $36-45$ & 9 & 20.93 & 2 & 5 \\
\hline & $46-55$ & 16 & 37.21 & 4 & 9.3 \\
\hline & $>56$ & 13 & 30.23 & 3 & 7 \\
\hline \multirow[t]{6}{*}{ Occupation } & Accreditor & 1 & 2.33 & 1 & 2.3 \\
\hline & Business analyst & 4 & 9.30 & 1 & 2.3 \\
\hline & $\begin{array}{l}\text { Consultant } \\
\text { Databse/IT coordinator }\end{array}$ & 7 & 16.28 & 2 & 5 \\
\hline & Manager 11 coordinator & 1 & 2.33 & 1 & 2.3 \\
\hline & Manager & 16 & 37.21 & 4 & 9.3 \\
\hline & & 14 & 32.56 & 1 & 2.3 \\
\hline \multirow[t]{6}{*}{ City } & Adelaide & 5 & 11.63 & 1 & 2.3 \\
\hline & Brisbane & 6 & 16.28 & 2 & 5 \\
\hline & Canberra & 6 & 16.28 & 1 & 2.3 \\
\hline & Melbourne & 8 & 18.60 & 3 & 7 \\
\hline & Sydney & 11 & 25.58 & 2 & 5 \\
\hline & Perth & 7 & 16.28 & 1 & 2.3 \\
\hline \multirow[t]{2}{*}{ Job classification } & Fixed term contract & & 16.28 & 2 & 5 \\
\hline & Permanent full-time & 36 & 83.72 & 8 & $\begin{array}{c}5 \\
19\end{array}$ \\
\hline \multirow{4}{*}{$\begin{array}{l}\text { ICT work } \\
\text { experience (years) }\end{array}$} & $10-19$ & 7 & 16.28 & 3 & 7 \\
\hline & $20-29$ & 10 & 23.26 & 3 & 7 \\
\hline & $30-39$ & 16 & 37.21 & 2 & 5 \\
\hline & $>40$ & 10 & 23.26 & 2 & 5 \\
\hline
\end{tabular}

Table 4: Characteristics of the interviewees

The transcribed interviews were analysed using thematic (qualitative) analysis with the help of QSR NVivo 10. The unit of analysis was each transcribed interview document. Data analysis proceeded as follows. First, the researchers read the interview documents several times in order to familiarise themselves with the data collected. Next, themes were created based on keywords and key topics in the interview documents. Researchers discussed the themes, and agreed on the mutual approach they were going to use to code text for each theme. Text with the same themes was located within the interview documents and assigned to these themes. Themes then acted as "buckets" in the sense that they held all the data related to a specific theme. These themes were then further divided into specific sub-themes. This was to create a hierarchy that made it easy to make sense of the data and facilitate interpretation.

\subsubsection{Findings from the qualitative interviews}

Findings from the 43 interviews that were conducted as part of the larger research project are rich and wide-ranging. For the purpose of this paper, our focus is on the forms that bullying can take in the ICT workplace, as identified by the interviewees.

\section{The forms that bullying takes in the ICT workplace}

Participants highlighted several forms that bullying can take. These are compared with five groups of bullying behaviours identified by Harvey et al. (2006). First, interviewees reported that bullying behaviour in the ICT workplace does include isolation of a victim through preventing their access to opportunities. Interviewee 13 explains: "Where I don't like that person so I'll give all the interesting work to that other person and if I just don't give any interesting work to that person, maybe they'll go away". This quote also shows that bullying can be intended and it can be purposeful in encouraging some employees to leave the organisation. Other interviewees also reported that the end goal of bullying behaviour is to destroy other people's careers. Interviewee 41 emphasised "he just got rid of them, he actually got rid of them" and the reason for this is that "he didn't like the fact they said he couldn't have 
an Apple Mac or whatever". Such behaviour can have significant repercussions for the employers in terms of cost of recruiting and potentially training a new employee.

Another way to isolate a victim is done through withholding important information. Interviewee 12 described this behaviour as "sabotage": "that's where you get some information that is disingenuous and they say okay go and do this work and you will go and conduct the work but really the intention is for you to never be successful in doing that work". The intent behind such behaviour is malicious. The bully gives their victim a task that (s)he will fail at. This is intended behaviour that is practised covertly.

The second form of bullying identified by Harvey et al. (2006), threats to personal standing by insulting or teasing the victim was also mentioned by several interviewees. An example with sending inappropriate emails or text messages, described by Interviewee 24 is related to this: "So a guy was fired for a text that was commenting on a girl or something like that. ... It was saying she's was really overweight". From this example it is clear that employers do take action when they have a written record as evidence of bullying.

However, as discussed earlier, bullying behaviour is not always overt and easy to notice. This makes bullying behaviours hard to stop in the workplace. Furthermore, employees may fear retribution and thus tolerate bullying behaviour, rather than report it. Interviewee 12 emphasised that the fear of retribution is particularly strong in branch locations "where things are smaller and it becomes more obvious if there are differences or accusations made". Thus, when Interviewee 23 states that there was never any bullying or a harassment charge in her/his organisation, the question remains if this is indeed due to absence of bullying, or because it has not been discovered yet. Interviewee 28 agrees with the latter option when (s)he informs that "the corporate psychopath still lives and the bully will still thrive on". This example questions the success of organisational approaches to dealing with bullying such as "they described bullying and they sent out DVDs, educational DVDs and they got a policy written about it" (Interviewee 12). Interviewees 28 pointed to a failure with this formal approach: "the corporate can say we've provided the training, but the actual one-on-one follow-up wasn't there". Hence, a different strategy was suggested that might be more successful, and that is "to talk about levels of informal discussions with management and perhaps a support person" (Interviewee 17).

Bullying behaviour can also take a physical form. Interviewee 31 remembered a situation: "she boiled over one day and this poor guy was out near the coffee machine making himself a cup of coffee and she physically came over and pushed him and nearly spilt some hot water on him and swore at him". In this example, the bully is a female, and the victim is a young man, age between 19 and 21. This is contrary to the findings in the literature that bullies are mostly men (Hauge et al., 2009). Interviewee 31 further explained that the "poor guy' from this example was "trying to hold his emotions back saying ...I don't know what I did to her". This indicates that bullying behaviour is not necessarily related to anything that a victim did or said, but it can be based on their lack of experience or power in the organisation. Comment from Interviewee 25 indicates that bullying behaviour is in the eyes of the perceiver, and it may not be recognised or intended by the so called bully "if a person feels they've been bullied then it is bullying, but from the other person's point of view they just thought they were having that kind of casual banter, chat".

The third type of bullying behaviour identified by Harvey et al. (2006) includes overwork through an increase of workload to targeted individuals. This was mentioned by Interviewee 41 who explained that bullying can also involve exerting "pressure" on employees "to produce results". Surprisingly Interviewee 41 also explained that bullying can also mean enforcing "poor processes" or "hiring the wrong people". This is particularly detrimental for the organisational success, and can create a range of further issues in the long run.

Thematic analysis of 43 interviews with Australian ICT employees provided some rich insights into the bullying behaviour in the Australian ICT workplace. However, we haven't found evidence of two of the bullying behaviours identified by Harvey et al. (2006). The first one is in relation to destabilising the victim by reminding them of their failures, and the second one 
is in relation to threats to victim's professional status. In addition, interviewees included two essential aspects of workplace bullying commonly used in the literature, occurrences of a negative behaviour and some form of harm that such behaviour causes to the target (Crawshaw, 2009). Our discussion on the findings from the qualitative interviews also highlights that bullying behaviour in the Australian ICT workplace involves unprofessional behaviour in a workplace, and that it is intentional. These are two aspects of bullying behaviour not commonly included in the literature (Saunders et al., 2007).

\section{Comparison between the survey participants and interviewees who raised the issue of bullying in the survey/interview}

Since the GLMs revealed that participants' Age, Gender, Geographic Location, Job Classification and Years of Experience all predict the selection of bullying as a response in the quantitative survey, it is worth comparing the percentage of the survey participants who identified bullying as an ethical issue with the percentage of the interviewees who brought up bullying during interviews.

In terms of age, $14.3 \%$ of the interviewees who raised the issue of bullying were between 36 and 55 years of age. This is inconsistent with the percentage of those who selected bullying in the survey. That is, in the survey $51.2 \%$ of those who selected bullying as one of the common ethical problems in the survey were between 36 and 55 years of age. However, the percentages are similar with regards to gender and geographic location although the influence of these two aspects is smaller because the vast majority of participants are males anyway and all interviews were conducted in state capital cities.

The percentage of the survey participants who selected bullying and the percentage of the interviewees, who raised the issue of bullying, are also dissimilar in the area of years of experience. Whereas $61.69 \%$ of the survey participants who selected bullying had more than 20 years of experience in IT, only $16.3 \%$ of the interviewees who raised the issue of bullying during interviews had more than 20 years of experience in IT.

However, a similarity between the percentage of the survey participants who identified bullying as an ethical issue and the percentage of the interviewees who raised the issue of bullying during interviews exists in the job classification area. While $13.2 \%$ of those who selected bullying in the quantitative survey classified their jobs as fixed term contracts, $13.9 \%$ of the interviewees, who raised the issue of bullying during interviews, indicated they are employed on the fixed term contract. This is a surprising finding and should be further examined in future.

\section{Discussion}

The statistical analysis showed that Age, Gender, Geographic Location, Job Classification and Years of Experience all predict the survey respondents' selection of bullying. However, in comparison with the demographic characteristics of the interviewees who raised the issue of bullying during the interviews, there is a mismatch. In terms of age, $14.3 \%$ of the interviewees who brought up the issue of bullying during interviews were between 36 and 55 years of age compared to $51.2 \%$ of the same age groups who selected bullying as one of the most common ethical problems in the survey. Notelaers, et al. (2011) found that employees between 36 and 55 years of age are more likely to be bullied at work compared to those above 54 years and those less than 25 years of age. However, Skinner et al. (2015), has indicated that older employees are more likely to be bullied than their counterparts. Further research is needed to shed light on both; the inconsistency in the literature and the inconsistency between the findings from the survey and the findings from the interviews.

In terms of gender and geographic location the proportion of the survey participants who identified bullying is similar to the proportion of the interviewees who brought up this issue but the influence of these two variables is smaller because the vast majority of participants are males and all interviews were conducted in state capital cities. There is also a similarity 
between the proportions of the survey participants and the interviewees in the job classification area. In the quantitative survey $13.2 \%$ of those who selected bullying classified their jobs as fixed term contracts whereas in the interviews $13.9 \%$ classified their jobs as fixed term contracts. Interestingly, Skinner et al. (2015) also found geographic location (i.e. city vs. regional) and job classification (i.e. length of current employment, continuing position and appointment) were predictive of the self-reporting of bullying in addition to individuals' background (i.e. being indigenous, speaking English at home and age). But since in the academic sector Skinner et al. (2015) found that the rate of bullying of academic staff was higher in regional universities than in metropolitan ones and given this study found geographic location to be a predictor of bullying, future research could compare bullying in metropolitan ICT workplaces with those in regional areas. Hopefully, this paper will pave the way for such future research.

In the area of years of work experience the proportion of the survey participants who selected bullying and the proportion of the interviewees who raised this issue are also dissimilar (61.69\% of survey participants compared to $16.3 \%$ of the interviewees had more than 20 years of experience in IT). Cowie et al. (2000) found that the length of current job was the only demographic characteristic that significantly correlates experiencing bullying behaviours in their UK sample. While this may explain why a significant proportion of survey participants with more than 20 years of experience selected bullying, it does not explain why a smaller proportion of the interviewees who had more than 20 years of experience selected bullying. Further research is needed to understand better the correlation between bullying and years of experience.

In terms of the forms that bullying takes in the ICT workplace, the qualitative in-depth interviews highlighted several forms. Bullying can be practiced covertly by someone giving another person a task that he/she knows the other person will fail at, to set them up for failure, or by not giving them work at all to deny them opportunities to flourish or by giving them the wrong information or withholding the information that they need to complete their tasks to sabotage their efforts or not including them in groups to make them feel excluded or isolated. Bullying can also be practiced overtly by nit-picking over someone's work or publically defaming or harassing them or by making or emailing offensive comments or by being physically aggressive. The frames of exerting "pressure" on employees "to produce results", or enforcing "poor processes", or "hiring the wrong people" can all be categorised under 'corporate bullying'. With the exception of two frames that were not reported by the participants in Harvey's et al. (2006) study, namely 'destabilising the victim by reminding them of their failures' and making threats to a victim's professional status, all the other frames reported in this study were highlighted in Harvey's et al. (2006) study. For example, the participants in the current study and Harvey's et al. (2006) study identified isolation such as by denying access to opportunities or withholding important information. They also identified overwork and threats to personal standing such as by insulting or teasing the victim.

\section{Conclusion}

The aim of this study was to examine bullying in the workplace from the perspective of Australian Information Communication Technology (ICT) professionals. The data collection for this project included conducting a quantitative survey and conducting qualitative interviews. The methods related to each other in this way: the quantitative survey identified bullying as the ninth from the top in the list of the most common ethical problems experienced by ICT professionals $(\mathrm{N}=630,27.2 \%)$ (see Table 2). The findings from the survey helped shape both the content of the follow-up interviews and the selection of those interviewed. The findings from the qualitative interviews highlighted the forms that bullying takes in the Australian ICT workplace.

A significant relationship was found between respondents' selection of bullying as a survey response and Job Classification. Job Classification, among other factors, predicted respondents' selection of bullying. In both the survey and interviews fixed term contracts had 
a greater concern about bullying than the permanent professionals. Obtaining such findings would not have been possible had only one data collection method been used.

This paper reported on different aspects of bullying in the Australian ICT industry as identified by ICT professionals. This is important for developing appropriate anti-bullying strategies in the workplace (Standen, Paull \& Omari, 2014). In addition, the findings reported in this paper point to a specific group of ICT professionals based on their demographic characteristics who identified workplace bullying as an ethical issue in the survey. This is an important finding that raises additional questions, such as do more fixed term contracts have a greater concern about bullying than the permanent ICT professionals and how bullying affects the bullied and those who are witnessing the bullying.

The research presented in this paper makes three contributions to the literature on workplace bullying in the ICT workplace. First, the paper highlighted the forms that bullying takes in the ICT workplace. Second, the paper offered a comparison between the forms that bullying takes in the ICT workplace and those in other workplaces as discussed in the literature. It is anticipated that this discussion will not only stimulate debate among researchers interested in this area, but that it will also raise the readers' awareness about these forms. The third, and arguably the most important contribution, was the discovery that the group of participants, who selected bullying in the survey and raised the issue of bullying during the qualitative interviews, were not the likely victims, but more likely the witnesses of such behaviour in the workplace.

Two limitations to the present study are outlined. One limitation is that not all survey participants volunteered to do interviews; only 419 survey participants (21.6\%) expressed an interest in taking part in interviews. Another limitation is that a higher proportion of full time employees and those on fixed term contracts participated in the interviews. This could have skewed the results of this analysis, as participants with other job classifications did not participate in the interviews.

In terms of suggestions for future research, the finding that $13.2 \%$ of those who selected bullying in the quantitative survey classified their jobs as fixed term contracts and $13.9 \%$ in the interviews classified their jobs as fixed term contracts is interesting. It is not clear why this group of ICT professionals, who are the unlikely victims of bullying, selected bullying as a response in the survey and raised this issue during interviews. Is it possible that these external professionals suffered while observing this wrongdoing happening to others? Or does this mean that fixed term contracts have a greater concern about bullying than the internal employees? Only future research can reveal the answers to these questions. Also, the literature indicates that bullying negatively affects those who witness this behaviour, and in our study it is possible that these participants also suffered while observing the bullying. However, this is a question for future research. That is, a future study could compare the effect of bullying in the ICT workplace on the victims of this behaviour with those who witness the occurrence of bullying incidents. Hopefully, this paper will pave the way for such future research.

Organisations have an ethical responsibility to provide employees with a safe workplace. This means that they are responsible for preventing workplace bullying, which is a major issue that impacts health and productivity of employees as well as organisations. Workplace bullying has rarely been investigated in the context of the ICT industry, although the speed of change and levels of stress that ICT professionals experience are strong indicators of high probability of bullying (Hauge et al., 2009).

\section{Acknowledgments}

The research reported here is supported by an Australian Research Council Linkage grant (LP130100808), for which the industry partner is the Australian Computer Society. Other team investigators were Professor John Weckert, A/Prof Oliver Burmeister and Mr John Ridge. The authors wish to thank A/Prof Oliver Burmeister for his significant contribution to the project in general and specifically for helping with the distribution of the survey, conducting some of the qualitative interviews and his suggestions with regards to the analysis 
of qualitative data. The authors also wish to thank Katherine Bell for editing an earlier draft of this paper.

\section{References}

Adam, A. (2000). Gender and computer ethics. ACM SIGCAS Computers and Society, 30(4), 17-24.

Al-Saggaf, Y., Burmeister, O. K., \& Weckert, J. (2016). Perceptions of Incompetence in the ICT workplace. ACM SIGCAS Computers and Society, 45(3), 11-17

Al-Saggaf, Y. \& Burmeister, O.K. (2013). A survey of Australian ICT professionals' perceptions regarding the most common ethical problems they face in the workplace. In M. Warren (Eds.). Proceedings of the Seventh AICE Conference (pp. 43-48). RMIT, Melbourne, Australia. December 3, 2013.

Bjorkqvis, K., Osterman, K., \& Hjelt-Back, M. (1994). Aggression among university employees. Aggressive Behavior, 20(3), 173-184.

Bowling, N. A., \& Beehr, T. A. (2006). Workplace harassment from the victim's perspective: a theoretical model and meta-analysis. Journal of Applied Psychology, 91(5), 998.

Claybourn, M. (2011). Relationships between moral disengagement, work characteristics and workplace harassment. Journal of Business Ethics, 100(2), 283-301.

Cowie, H., Jennifer, D., Neto, C., Angula, J. C., Pereira, B., Del Barrio, C., \& Ananiadou, K. (2000). Comparing the nature of workplace bullying in two European countries: Portugal and the UK. Transcending boundaries: Integrating People, Processes and Systems, 128-133.

Crawshaw, L. (2009). Workplace bullying? Mobbing? Harassment? Distraction by a thousand definitions. Consulting Psychology Journal: Practice and Research, 61(3), 263.

Cuyper, N., Notelaers, G., \& Witte, H. (2009). Transitioning between temporary and permanent employment: A two-wave study on the entrapment, the stepping stone and the selection hypothesis. Journal of Occupational and Organizational Psychology, 82(1), 67-88.

Einarsen, S., \& Raknes, B. I. (1997). Harassment in the workplace and the victimization of men. Violence and Victims, 12(3), 247-263.

Einarsen, S., \& Skogstad, A. (1996). Bullying at work: Epidemiological findings in public and private organizations. European Journal of Work and Organizational Psychology, 5(2), 185-201.

Griffiths, M., \& Moore, K. (2010). 'Disappearing Women': A Study of Women Who Left the UK ICT Sector. Journal of Technology Management \& Innovation, 5(1), 95-107.

Gutek, B. A., \& Morasch, B. (1982). Sex-ratios, sex-role spillover, and sexual harassment of women at work. Journal of Social Issues, 38(4), 55-74.

Harvey, M. G., Heames, J. T., Richey, R. G., \& Leonard, N. (2006). Bullying: From the playground to the boardroom. Journal of Leadership \& Organizational Studies, 12(4), 1-11.

Hauge, L. J., Skogstad, A., \& Einarsen, S. (2009). Individual and situational predictors of workplace bullying: Why do perpetrators engage in the bullying of others? Work \& Stress, 23(4), 349-358.

Hoel, H., Cooper, C. L., \& Faragher, B. (2001). The experience of bullying in Great Britain: The impact of organizational status. European Journal of Work and Organizational Psychology, 10(4), 443-465. 
Jóhannsdóttir, H. L., \& Ólafsson, R. F. (2004). Coping with bullying in the workplace: the effect of gender, age and type of bullying. British Journal of Guidance \& Counselling, 32(3), 319-333.

Keashly, L., \& Neuman, J. H. (2004). Bullying in the workplace: Its impact and management. Employee Rights and Employment Policy Journal, 8, 335-523.

Kelloway, K., Bryant, M., Buttigieg, D., \& Hanley, G. (2009). Poor bullying prevention and employee health: some implications. International Journal of Workplace Health Management, 2(1), 48-62.

Kivimäki, M., Virtanen, M., Vartia, M., Elovainio, M., Vahtera, J., \& Keltikangas-Järvinen, L. (2003). Workplace bullying and the risk of cardiovascular disease and depression. Occupational and Environmental Medicine, 6o(10), 779-783.

Leymann, H. (1993). Mobbing-Psychoterror am Arbeitsplatz und wie man sich dagegen wehren kann (Mobbing-psychoterror in the workplace and how one can defend oneself). Reinbeck: Rowohlt.

Leymann, H., \& Gustafsson, A. (1996). Mobbing at work and the development of posttraumatic stress disorders. European Journal of Work and Organizational Psychology, 5(2), 251-275.

Lucas, R., \& Mason, N. (2008). A survey of ethics and regulation within the ICT industry in Australia: Ethics education. Journal of Information, Communication and Ethics in Society, 6(4), 349-363.

Lucas, R., \& Weckert, J. (2008). Regulation in the ICT industry. Canberra: Centre for Applied Philosophy and Public Ethics, Australian National University.

Mason, E. S., \& Mudrack, P. E. (1996). Gender and ethical orientation: A test of gender and occupational socialization theories. Journal of Business Ethics, 15(6), 599-604.

Mudrack, P. E., \& Mason, E. S. (2013). Ethical judgments: What do we know, where do we go? Journal of Business Ethics, 115(3), 575-597.

Nielsen, M. B., Skogstad, A., Matthiesen, S. B., Glasø, L., Aasland, M. S., Notelaers, G., \& Einarsen, S. (2009). Prevalence of workplace bullying in Norway: Comparisons across time and estimation methods. European Journal of Work and Organizational Psychology, 18(1), 81-101.

Notelaers, G., De Witte, H., \& Einarsen, S. (2010). A job characteristics approach to explain workplace bullying. European Journal of Work and Organizational Psychology, 19(4), 487-504.

Notelaers, G., Vermunt, J. K., Baillien, E., Einarsen, S., \& De Witte, H. (2011). Exploring risk groups workplace bullying with categorical data. Industrial Health, 49(1), 73-88.

Oleksy, W., Just, E., \& Zapedowska-Kling, K. (2012). Gender issues in information and communication technologies (ICTs). Journal of Information, Communication and Ethics in Society, 10(2), 107-120.

Ortega, A., Høgh, A., Pejtersen, J., \& Olsen, O. (2009). Prevalence of workplace bullying and risk groups: a representative population study. International Archives of Occupational and Environmental Health, 82(3), 417-426.

Quigley, B. Z., \& Mohamad, S. (2008). Gender, the propensity for ethical behavior and the bottom line. Journal of Business and Behavioral Sciences, 19(20), 46-57.

Rodríguez-Muñoz, A., Moreno-Jiménez, B., Sanz Vergel, A. I., \& Garrosa Hernández, E. (2010). Post-Traumatic symptoms among victims of workplace bullying: Exploring gender differences and shattered assumptions. Journal of Applied Social Psychology, 40(10), 2616-2635. 
Salin, D. (2001). Prevalence and forms of bullying among business professionals: A comparison of two different strategies for measuring bullying. European Journal of Work and Organizational Psychology, 10(4), 425-441.

Salin, D. (2003a). The significance of gender in the prevalence, forms and perceptions of workplace bullying. Nordiske Organisasjonsstudier, 5(3), 30-50.

Salin, D. (2003b). Ways of Explaining Workplace Bullying: A Review of Enabling, Motivating and Precipitating Structures and Processes in the Work Environment. Human Relations, 56(10), 1213-1232.

Saunders, P., Huynh, A., \& Goodman-Delahunty, J. (2007). Defining workplace bullying behaviour professional lay definitions of workplace bullying. International Journal of Law and Psychiatry, 30(4-5), 340-354.

Sheehan, M., McCarthy, P., Barker, M., \& Henderson, M. (2001). A model for assessing the impacts and costs of workplace bullying. Article presented at the Standing Conference on Organizational Symbolism (SCOS), Dublin, UK.

Skinner, T. C., Peetz, D., Strachan, G., Whitehouse, G., Bailey, J., \& Broadbent, K. (2015). Selfreported harassment and bullying in Australian universities: explaining differences between regional, metropolitan and elite institutions. Journal of Higher Education Policy and Management, 37(5), 558-571.

Standen, P., Paull, M., \& Omari, M. (2014). Workplace bullying: Propositions from Heider's balance theory. Journal of Management \& Organization, 20(6), 733-748.

Valentine, S., \& Page, K. (2006). Nine to five: Skepticism of women's employment and ethical reasoning. Journal of Business Ethics, 63(1), 53-61.

Vartia, M. (1996). The sources of bullying-psychological work environment and organizational climate. European Journal of Work and Organizational Psychology, 5(2), 203-214.

Vartia, M. A.-L. (2001). Consequences of workplace bullying with respect to the well-being of its targets and the observers of bullying. Scandinavian Journal of Work, Environment \& Health, 27(1), 63-69.

Wilford, S. H., \& Wakunuma, K. J. (2014). Perceptions of ethics in IS: how age can affect awareness. Journal of Information, Communication and Ethics in Society, 12(4), 270283.

Young, K. S., \& Case, C. J. (2009). Computer ethics: Gender effects and employee internet misuse. Issues in Information Systems, 10(2), 598-603.

Zapf, D. (1999). Organisational, work group related and personal causes of mobbing/bullying at work. International Journal of Manpower, 20(1/2), 70-85.

Copyright: (C) $2017 \mathrm{Al}$-Saggaf \& Ceric. This is an open-access article distributed under the terms of the Creative Commons Attribution-NonCommercial 3.0 Australia License, which permits non-commercial use, distribution, and reproduction in any medium, provided the original author and AJIS are credited. 


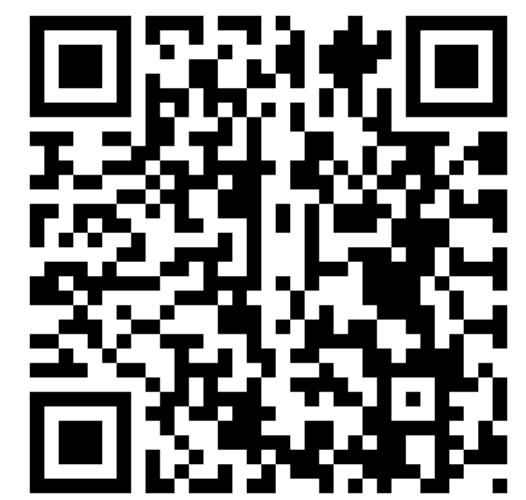

